2020 Global Marketing Conference at Seoul Proceedings: 1621-1624 (November 2020) https://doi.org/10.15444/GMC2020.11.05.27

\title{
FIRM PERFORMANCE THROUGH ONLINE ENGAGEMENT: THE ROLE OF EXPERIENCE AND CUSTOMER INSPIRATON
}

\author{
Muhammad Al-Reesh, Instituto Universitário de Lisboa (ISCTE-IUL) and Business \\ Research Unit (BRU-IUL), Portugal ${ }^{1}$ \\ Sandra Maria Correia Loureiro, Instituto Universitário de Lisboa (ISCTE-IUL) and \\ Business Research Unit (BRU-IUL), Portugal ${ }^{2}$ \\ Ricardo Godinho Bilro, Instituto Universitário de Lisboa (ISCTE-IUL) and Business \\ Research Unit (BRU-IUL), Portugal ${ }^{3}$
}

\begin{abstract}
This research aims to assess the current status of online trade relations between Kuwait and Portugal. To do so, we examine how firm managers from Portugal and Kuwait use online platforms to engage customers to enhance firm performance. A set of existing constructs was chosen (Online Experience, Customer Inspiration, Online Customer Engagement, Firm Performance, National Culture), which were included in a proposed model of structural equations, in order to assess the contribution of Online Experience and Customer inspiration to the current status of online trade relations (through Online Customer Engagement), and how these can be improved to the further development of e-commerce between the two countries.
\end{abstract}

\section{Online Experience}

The customer experience (CE) is the experience customers have when they interact with a brand. New progress in mobile technology and its acceptance by many consumers have made it vital for firms to reshape interaction and service delivery features to attain an ideal online user experience (Siwicki, 2014). Organizations today must discover a way to build emotional connections with their users on their mobile devices and let their customers provide feedback (Cheung et al., 2015). Customer experience is defined as customers' perceptions - both conscious and subconscious of their relationship with our brand resulting from all their interactions with some brand during the customer life cycle (Ebenezer Paul Rajan and Vardharaj, 2015).

Klaus (2013) identified the functionality and psychological factors as the central dimensions of online customer experience. Klaus (2013, p. 445) defined online customer service experience as “...the customers' mental perception of interactions with a company's value proposition online. These are mental perceptions in turns to drive a set of outcomes, namely, benefits, emotions, judgments, and intentions." There has been a considerable increase and shift in online shopping behavior as customers have started using Internet-enabled multi-devices (Wagner et al., 2013)

\section{Customer Inspiration (CI)}

\footnotetext{
dinnis6@hotmail.com

2 sandramloureiro@netcabo.pt

3 ricardo.bilro@iscte-iul.pt
} 
Customer Inspiration (CI) in marketing involves different goals, recipients, and sources of inspiration. The marketing domain seems sufficiently different from prior areas of inspiration research (e.g., general psychology, education, sports, creativity) to warrant a domain-specific conceptualization and measurement (Kassarjian, 1971; Aaker,1997). A standardized scale is preferred to this practice because its reliability and validity have established, and its use enables comparisons across studies (Goldsmith \& Hofacker, 1991).

Inspiration thus bridges the gap between the deliberation phase (i.e., goal setting) and the implementation phase (i.e., goal-striving) of goal pursuit (Gollwitzer, 1990). The intent to inspire customers should lie at the heart of marketing, yet CI has received little attention in prior research. By conceptualizing CI and by developing a sound measure for this new construct, our study establishes the first step toward firmly embedding inspiration in management practice.

\section{Online Customer Engagement}

Customer engagement is a term that has known increased attention within services marketing literature. Customer engagement, or $\mathrm{CE}$, has been defined as a "...psychological process that models the underlying mechanisms by which customer loyalty forms and the mechanisms by which loyalty may explore..." (Bowden, 2009, p. 65).

In their definition of $\mathrm{CE}$, Brodie et al. (2011) conceptualized engagement as a contextually contingent process that can differ in cognitive, emotional, and behavioral intensity. Several studies prompt future research to explore how CE operates across various contexts (Brodie et al., 2011; Vivek, 2009; Wirtz, 2013). A hedonic and utilitarian service typology may provide such a variety, as it encompasses a range of services that differ in their core consumption purposes (Ng et al., 2007).

Across marketing literature, customer-provider relationships have typically explored through the various constituents of a customer's connection with a brand, such as loyalty, satisfaction, and participation. Though these constructs may function as individual aspects of brand relationships, they do not define the nature and depth of how brand relationships form and how they sustained. Nevertheless, the concept of $\mathrm{CE}$ covers this individualistic perspective by delivering marketers a significant process that includes the total set of brand-focused activities that encourage customers to form close, emotional and valued bonds with service providers (Bowden, 2009; Gummerus et al., 2012).

\section{Firm performance (FP)}

Today, performing well with a high degree of customer orientation is vital for the survival of any company (Feng, Wang, Lawton \& Luo, 2019). Therefore, evaluating and measuring business performance is vital since companies are pursuing effective and efficient results. However, due to the absence of a consensual operational definition of FP, there are diverse interpretations of its meaning. Definitions of this concept may be abstract, or general, less or clearly defined (Taouab \& Issor, 2019). FP is a relevant construct in management research and frequently used as a dependent variable. Despite its relevance, there is scarcely any consensus about its definition, 
dimensionality, and measurement, limiting advances in research. It suffers from limited conceptualization, selection of indicators based only on convenience, and no proper consideration of its dimensionality.

\section{National Culture- moderating variables}

In the last decades of the 20th century, researchers tried to settle an ancient question: why do societies behave so dissimilarly from each other? One of the most famous essayists is Hofstede $(1980,1984)$ with a seminal work that defined five big cultural dimensions: power distance, uncertainty avoidance, individualism vs. collectivism, masculinity vs. femininity, and secondarily added - short vs. long term orientation. Other authors ensued, approaching these issues, with some of them disagreeing regarding the dimensionality, nature, grouping, or temporality of those components. Recently, the field turned its eyes into how different cultures connect with the world of online commerce and how willing citizens and companies are to trust these new tools and agents.

The other facet that may play an instrumental role in the proposed model is the Type of Industry. Therein, various business realities come into play: services vs. mass manufacturing, which in more detail presupposes different types of work routines, touchpoints (online or offline) between buyers and sellers and a manifold of exchanging relationships like $\mathrm{B} 2 \mathrm{~B}, \mathrm{~B} 2 \mathrm{C}, \mathrm{B} 2 \mathrm{E}, \mathrm{B} 2 \mathrm{G}, \mathrm{B} 2 \mathrm{M}, \mathrm{C} 2 \mathrm{~B}, \mathrm{C} 2 \mathrm{C}$ and others (Pons, Aljifri \& Fourati, 2003; Nemat, 2011) in traditional and electronic commerce.

This research to understand the current relationship of e-commerce between the two countries, how does such a process could be helpful to write a new page in the economic and diplomatic history between Portugal and Kuwait. Furthermore, how to fulfill the gap found in the literature, while shedding new light upon the chosen constructs, the Social Exchange Theory (SET) was elected the theoretical framework for the research project. An outline of the proposed model and a brief description of the constructs as given below.

The motivation of this research to address the status of online trade relations between Portugal and Kuwait, the paper's findings will be expected to have managerial and diplomatic implications, setting the foundations for an international association composed of Portuguese and Kuwaiti corporate leaders/investors with guidelines for multicultural business deals that respect both countries laws and trading needs.

Keywords: firm performance, online engagement, customer inspiration, national culture

\section{REFERENCES}

Bowden, J.L.-H. (2009). The process of customer engagement: a conceptual framework. The Journal of Marketing Theory and Practice, 17(1), 63-74.

Brodie, R.J., Hollebeek, L.D., Juric, B. and Ilic, A. (2011). Customer engagement: Conceptual domain, fundamental propositions, and implications for research. Journal of Service Research, 14(3), 252-271.

Cheung, C.M., Liu, I.L. and Lee, M.K. (2015). How online social interactions inflence customer information contribution behavior in online social shopping communities: a social learning theory perspective. Journal of the Association for Information 
Science and Technology, 66(12), 2511-2521.

Ebenezer Paul Rajan.T.Y. and A.Vardharaj, (2015). Customer Experience Management in Online Retailing- A Literature Review. International Journal in Commerce, IT \& Social Sciences (IJCISS), $\quad 2(2), 38-44$.

Feng, T., Wang, D., Lawton, A. and Luo, B. (2019). Customer orientation and firm performance: The joint moderating effects of ethical leadership and competitive intensity. Journal of Business Research, 100, 11-121.

Goldsmith, R. E. and Hofacker, C. (1991). Measuring Consumer Innovativeness. Journal of the Academy of Marketing Science, 19(3), 209-21.

Gollwitzer, P. M. (1990). Action phases and mind-sets. Handbook of motivation and cognition: Foundations of social behaviour, Sorrentino(Eds.), 2, 53-92. New York: Guilford.

Gummerus, J., Liljander, V., Weman, E. and Pihlström, M. (2012). Customer engagement in a Facebook brand community. Management Research Review, 35(9), 857-877.

Hofstede, G. (1980). Cultural consequences: international differences in work related values. Beverly Hills, C.A.: Sage.

Kassarjian, Harold H. (1971). Personality and Consumer Behaviour: A Review. Journal of Marketing Research, 8(4), 409-18

Klaus, P. (2013). The case of Amazon.com: towards a conceptual framework of online customer service experience (OCSE) using the emerging consensus technique (ECT). Journal of Services Marketing, 27(6), 443-457.

Nemat, R., (2011). Taking a look at different types of e-commerce. World Applied Programming, 1(2), 100-104.

Ng, S., Russell-Bennett, R. and Dagger, T. (2007). A typology of mass services: the role of service delivery and consumption purpose in classifying service experiences. Journal of Services Marketing, 21(7), 471-480.

Pons, A., Aljifri, H., Fourati, K. (2003). E-commerce and Arab intra-trade. Information Technology \& People, 16(1), 34-48.

Siwicki, B. (2014). E-commerce and m-commerce: the next five years. Internet Retailer, available at: http:/www.Internetretailer.com/commentary/2014/04/28/ecommerce- and-m-commerce-nextfie-years

Taouab O., Issor, Z. 2019. Firm Performance: Definition and Measurement Models. European Scientific Journal, 15(1), 93-106.

Wagner, G., Schramm-Klein, H. and Steinmann, S. (2013). Effects of cross-channel synergies and complementarity in a multichannel e-commerce system - an investigation of the interrelation of e-commerce, m-commerce and IETV-commerce. The International Review of Retail, Distribution and Consumer Research, 23(5), 571-581.

Wirtz, J., Den Ambtman, A., Bloemer, J., Horváth, C., Ramaseshan, B., Van de Klundert, J., Gurhan Canli, Z. and Kandampully, J. (2013). Managing brands and customer engagement in online brand communities. Journal of Service Management, 24(3), 223-244. 